Bangladesh J. Sci. Ind. Res. 43(1), 77-88, 2008

\title{
Studies on the Physico-Chemical Properties of Ceramic Tiles Produced from Locally Available Raw Materials
}

\author{
S. A. Jahan, S. Parveen*, S. Ahmed and M. Moniruz Zaman \\ Institute of Glass and Ceramic Research and Testing (IGCRT), Bangladesh Council of \\ Scientific and Industrial Research (BCSIR), Dr. Quadrat-i-Khuda Road, \\ Dhanmondi, Dhaka - 1205, Bangladesh.
}

\begin{abstract}
Due to the increasing demand of cost-effective tiles in Bangladesh, using the locally available raw materials five different batches of tiles have been prepared and their physical properties (firing shrinkage, bending strength, water absorption, bulk density etc.) as well as chemical properties were studied in order to evaluate the quality of the products. The present investigation revealed that various properties of the produced tiles are similar to those present in commercial tiles which are available in the local market.
\end{abstract}

Key words: Tiles, Firing shrinkage, Bending strength, Water absorption, Bulk density.

\section{Introduction}

Recently, the increasing demand of ceramic tiles for both the floor and wall has led the researchers to become interested in developing this field (Das, et. al 2005; Olgun, et. al 2005 and Shah and Maity, 2001) Particularly, fashionable but low cost ceramic tiles are very much lucrative for interior designing as well as for real estate housing developments. In fact, construction industry is now widely using ceramic tiles because of its variety of impressive colours, textures and design. Consequently, cost-effective and acceptable optimized methodologies for the manufacture of ceramic tiles are highly desirable. Specifically, utilisation of low cost, easily available natural resources (clay, feldspar, quartz etc.) as raw materials for ceramic tiles production has no doubt made a significant step forward in this regard. In ceramic tile compositions, an optimum combination or mixture of various ingredients and raw materials is considered as the key step, because the physico-chemical properties of tiles depend on such optimum conditions. In other words, in the development and manufacture of ceramic tiles, some basic

* Corresponding author 
physical properties such as firing shrinkage, water absorption, bulk density, bending strength etc. act as the quality control parameters, which ultimately depend on the chemical compositions of the raw materials. Hence, choice of raw materials with optimum ratio mixture is very much important. Moreover, since it is likely that the presence of impurity in different oxides may contribute to the unwanted colour of the fired products, the purity of the raw materials is also another factor. Considering these factors, two types of kaolinitic clays e.g. china clay and ball clay are widely used as major raw materials. However, among these two raw materials the later one is finer and provides higher plasticity in ceramic tile. The other suitable raw materials, which have considerable demand include; limestone, dolomite, marble etc. as the source of carbonate, since carbonate acts as fluxing mineral (Yatsenko et. al 1998. Shrinkage of tile during firing is another important problem, which should be minimized, because such effect no doubt will affect the regular size and shape of the ceramic body. To overcome this problem, addition of various calcium containing minerals (e.g. blast furnace slag, iron slag, fly ash, wollastonite) is an ideal choice to the researchers (Das et. al. 2005).

In the perspective of Bangladesh, a developing country, recently the demand and use of cost-effective ceramic tiles (both wall and floor) is increasing tremendously. Hence, utilization of locally available raw materials for the production of quality ceramic tiles is very important, because such step will obviously strengthen the economic condition of the country. Keeping this view in mind, we have attempted to develop quality tiles using the natural resources of clays as the raw materials available in Bangladesh. In this present study we have investigated various formulations of ceramic tiles using locally available clays (Mymensing clay, ball clay, quartz, feldspar and zircon). Five different batches of tiles were prepared incorporating different ratios of the raw materials and the physical properties (firing shrinkage, bending strength, water absorption, bulk density etc.) as well as chemical properties of the finished products were studied in order to evaluate the quality of the ceramic tile body.

\section{Materials and Methods}

In order to accomplish this study properly, detailed investigation was focused on:

(i) Choice of raw materials and their assessment through chemical and thermal analyses;

(ii) Formulation and preparation of five different batches of tiles;

(iii) Studies on the physico-chemical properties of the prepared tiles; and

(iv) Comparison with local tiles. 
Choice of raw materials and their assessment through chemical and thermal analyses

In order to fulfill the objective of the present study, choice of the locally available raw materials was very much important and in our selection Mymensing clay (M. clay) and ball clay (B. clay) got the priority as the source of clays due to their huge availability in many parts of our country. However, M. clay and B. clay were collected from Mymensing district. The additional raw materials used in this investigation were quartz, feldspar and zircon. Quartz and feldspar were purchased from local markets which are usually imported from India whereas zircon was collected from Cox's Bazar beach. Feldsper was used as a fluxing agent and quartz as filler. However, quantitative chemical analyses of all the raw materials were performed through the sophisticated X'ray fluorescence spectrophotometer (XRF, PANalytical XRF, Model no. PW2404) technique. Thermal behavior of the raw materials was studied by using a computerized TGA / DTA (Setaram, Labsys ${ }^{\mathrm{TM}}$ ) machine.

\section{Formulation and preparation of five different} batches of tiles

Having acquired the knowledge about the chemical constituents of the raw materials, compositions of five different batches of tiles body were formulated as shown in Table I.

Following the above proportions of the ingredients, one kg of each batch composition was prepared and subjected to ball milling for 4 days, which was then followed by drying at room temperature. It was then ground very well in order to achieve very fine powder with particle size less than 200 mesh. Particle size is an important factor since smaller particle size is very much desirable to obtain a quality product. However, at this stage the dry powder was thoroughly mixed with $10 \%$ aqueous solution of molasses, which acts as the binder and the mixture was then wrapped with poly

Table I. Compositions of five different batches of the tiles specimen

\begin{tabular}{c|c|c|c|c|c}
\hline Raw materials & Tile A\% & Tile B\% & Tile C\% & Tile D\% & Tile E\% \\
\hline M. clay & 50 & 55 & 50 & 0 & 60 \\
B. clay & 0 & 0 & 30 & 50 & 15 \\
Feldspar & 20 & 30 & 5 & 10 & 15 \\
Quartz & 30 & 15 & 15 & 30 & 10 \\
Zircon & 0 & 0 & 0 & 10 & 0 \\
\hline
\end{tabular}


thene to prevent any loss of moisture. It should be noted here that molasses is a waste product of the sugar industries of our country, which is easily available. After 7 days these composite mixture was ready to prepare the tile samples. Several rectangular bars $\left(2^{/ /} \times 2^{/ /} \times 0.45^{/ /}\right)$were prepared at a pressure of 5 tons using a hydraulic press. Such pressure helped to achieve the bars with compact shape which was first dried at $110^{\circ} \mathrm{C}$ followed by firing at $1050^{\circ} \mathrm{C}$ temperature (normal firing temperature of commercial wall tile bodies) in an electric furnace maintaining a soaking period of 15 min. to get the finished fired products. A flow diagram of the above mentioned preparation procedure is shown in Figure 1.

\section{Studies on the physico-chemical properties of} the prepared tiles and comparison with local tiles

This section describes the procedure adapted to investigate the physico-chemical properties of the finished products covering the comparison with the properties of commercially available tiles namely: Fu-Wang, Madhumati and R.A.K. These tiles were collected from the respected factories. The key physical properties (e.g. firing shrinkage, bending strength, water absorption, bulk density etc.) which control the quality of tiles were determined by following ASTM5. Modulus of rupture (MOR) was determined by Universal Testing Machine (Shimadzu

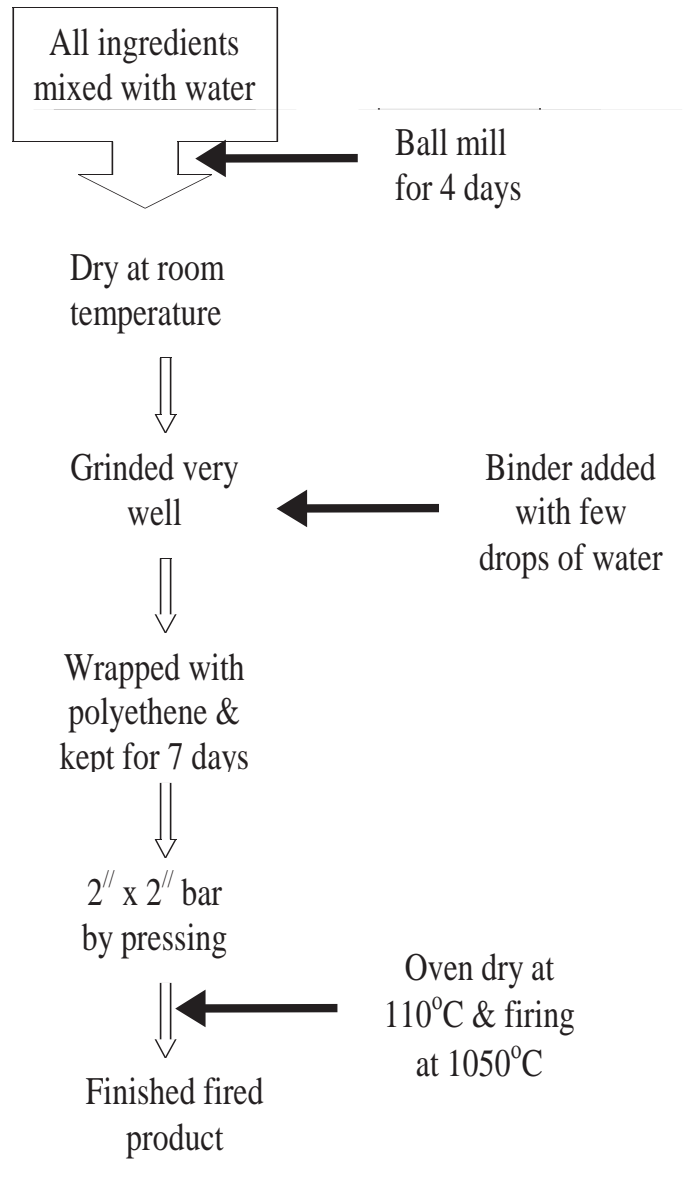

Fig. 1. Flow diagram of tile samples preparation from locally available raw materials

UTM, model AUTOGRAPH AGS-10KNG) Quantitative chemical analysis was done by using both XRF Spectrophotometer and conventional gravimetric method. All the chemicals used for this study were analar grade and the solutions were prepared using double distilled water. $\mathrm{Na}_{2} \mathrm{CO}_{3}, \mathrm{NH}_{4} \mathrm{Cl}, \mathrm{NH}_{4} \mathrm{OH}$, $\mathrm{HCl},\left(\mathrm{NH}_{4}\right)_{2} \mathrm{HPO}_{4}$ and ammonium oxalate were used as obtained from either E.Merk or $\mathrm{BDH}$. 


\section{Results and Discussion}

\section{(i) Physical characteristics, chemical and ther-} mal analyses of the raw materials

The physical characteristics of two major raw materials, M. Clay and B. Clay revealed that the later one is more plastic, which could be due to the variation in chemical composition. However, to determine the distinctive role of all the raw materials used in processing the ceramic tiles, it was first necessary to assess their chemical compositions. The chemical analyses of all the raw materials are shown in Table II. It is evident from this Table that in case of both the clays percentage of loss on ignition (L.O.I), silica and alumina are similar. However, the percentage of silica (44.00 - 46.00) of these two clays clearly indicates their kaolinitic nature. Moreover, the $\mathrm{Al}_{2} \mathrm{O}_{3} / \mathrm{SiO}_{2}$ ratio of these clays is around 0.8 which is very close to the theoretical ratio of pure kaolinite (0.85) (Halm, 1952). On the other hand chemical analysis of quartz shows that its purity is quite reasonable $\left(\mathrm{SiO}_{2}-99.00 \%\right)$ and feldspar is also quartzitic in nature.

The DTA analyses of all the raw materials are shown in Figures 2a - 2e. The B. clay and M. clay (Fig. 2a and 2b) indicate the presence of kaolinite which is revealed by the characteristic peaks in their usual positions. The endothermic peaks at around 500$600^{\circ} \mathrm{C}$ are due to loss of structural water present in the clay samples. The thermo gravimetric analyses of B. clay and M. clay show the weight loss in the region $530-580^{\circ} \mathrm{C}$

Table II: Chemical analysis of the raw materials

\begin{tabular}{c|c|c|c|c}
\hline \multirow{2}{*}{$\begin{array}{c}\text { Parameters meas- } \\
\text { ured (\%) }\end{array}$} & \multicolumn{4}{|c}{ Raw materials used } \\
\cline { 2 - 5 } & Feldspar & Quartz & M. clay & B. clay \\
\hline $\mathrm{L.O.I}$ & 0.677 & 0.476 & 13.740 & 12.002 \\
$\mathrm{Al}_{2} \mathrm{O}_{3}$ & 18.383 & --- & 35.795 & 36.929 \\
$\mathrm{SiO}_{2}$ & 65.092 & 99.152 & 45.892 & 44.628 \\
$\mathrm{Na}_{2} \mathrm{O}$ & 1.565 & --- & --- & 0.113 \\
$\mathrm{~K}_{2} \mathrm{O}$ & 13.647 & 0.368 & 0.100 & 0.738 \\
$\mathrm{CaO}$ & 0.146 & --- & 0.094 & 0.171 \\
$\mathrm{TiO}_{2}$ & ---- & --- & 2.509 & 3.565 \\
$\mathrm{Fe}_{2} \mathrm{O}_{3}$ & 0.067 & --- & 1.888 & 0.958 \\
$\mathrm{ZrO}_{2}$ & ---- & --- & 0.283 & 0.126 \\
$\mathrm{MgO}^{----}$ & --- & 0.153 & 0.442 \\
$\mathrm{Others}$ & 0.32 & --- & 0.084 & 0.331 \\
\hline
\end{tabular}




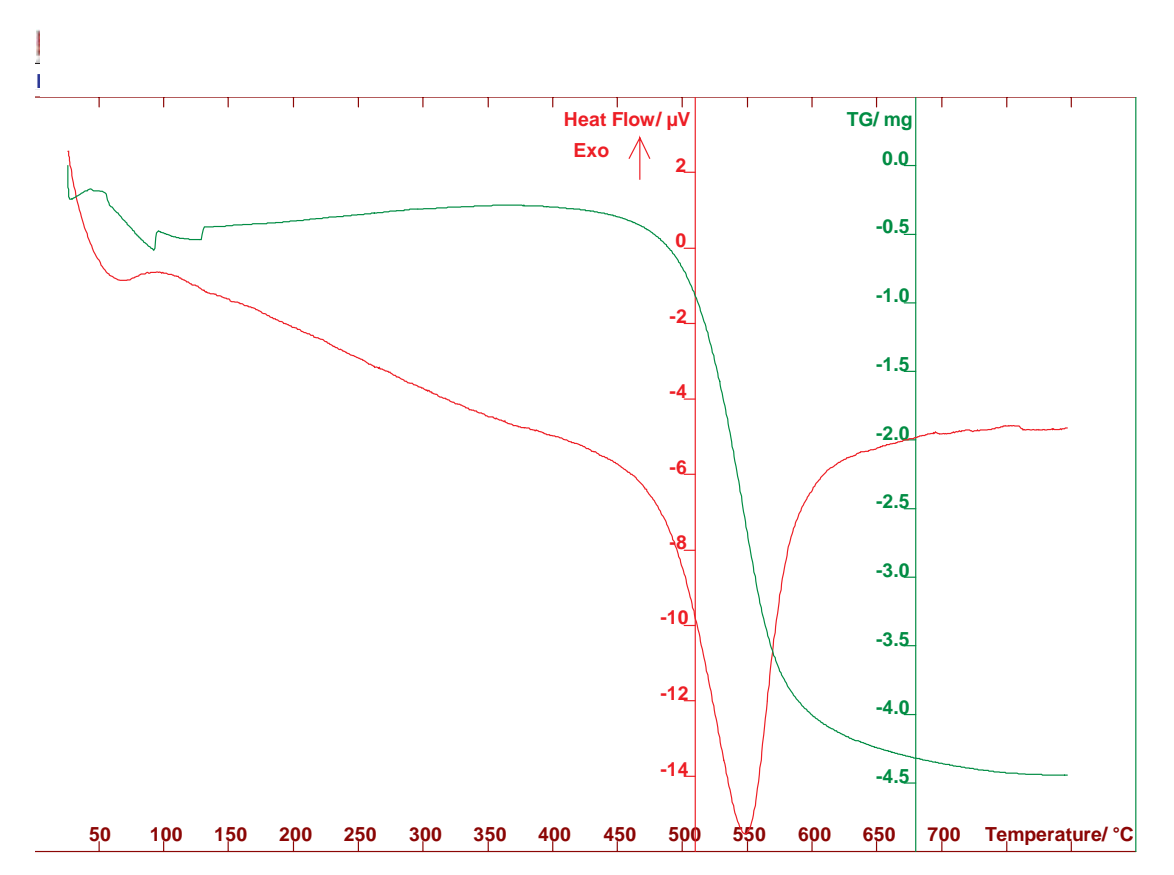

Fig. 2(a). DTA/TGA curves of B. clay

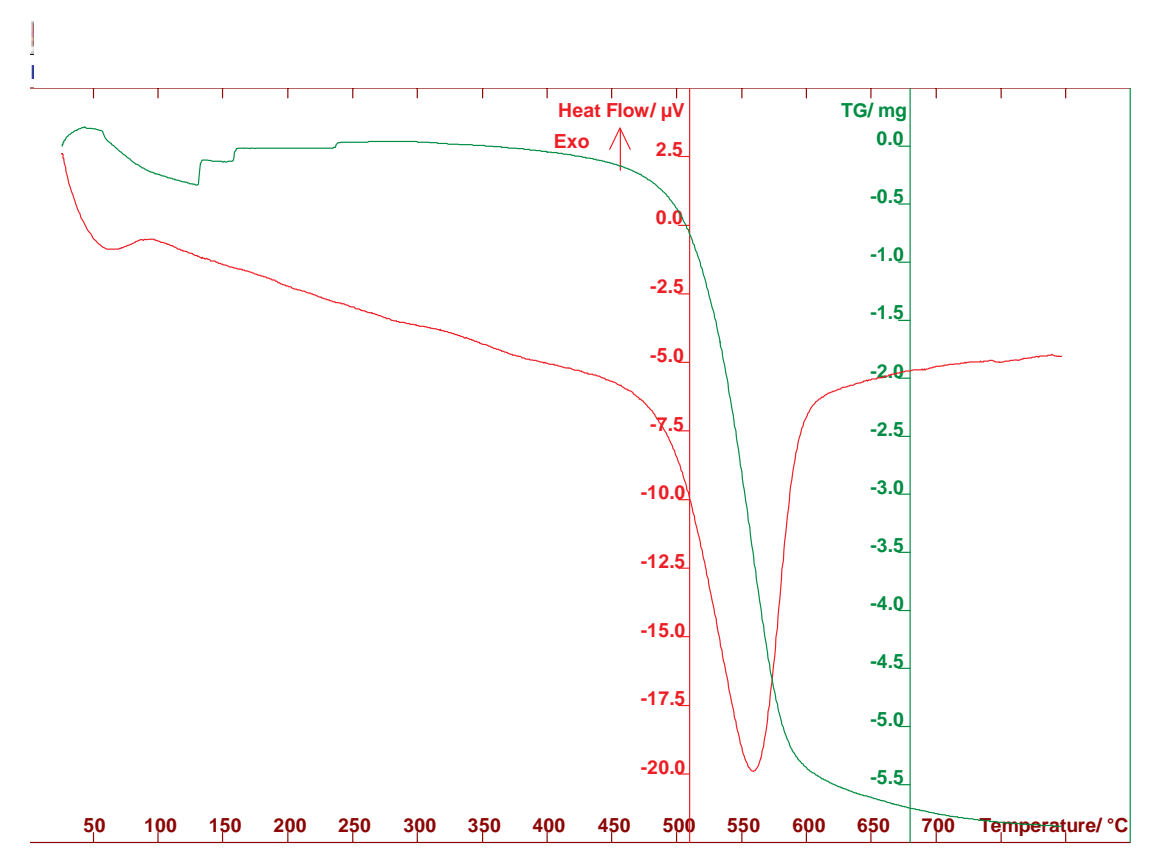

Fig. 2(b). DTA/TGA curves of M. clay 


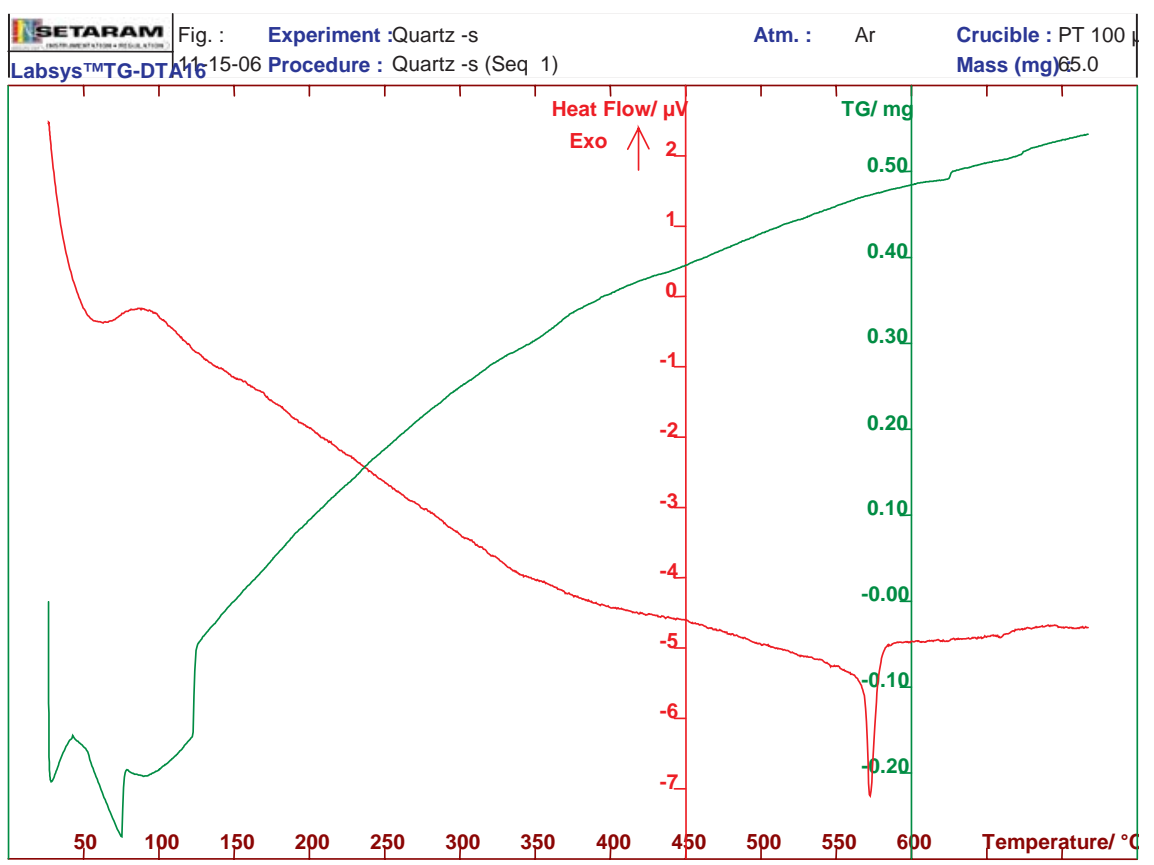

Fig. 2(c). DTA/TGA curves of quartz Figure

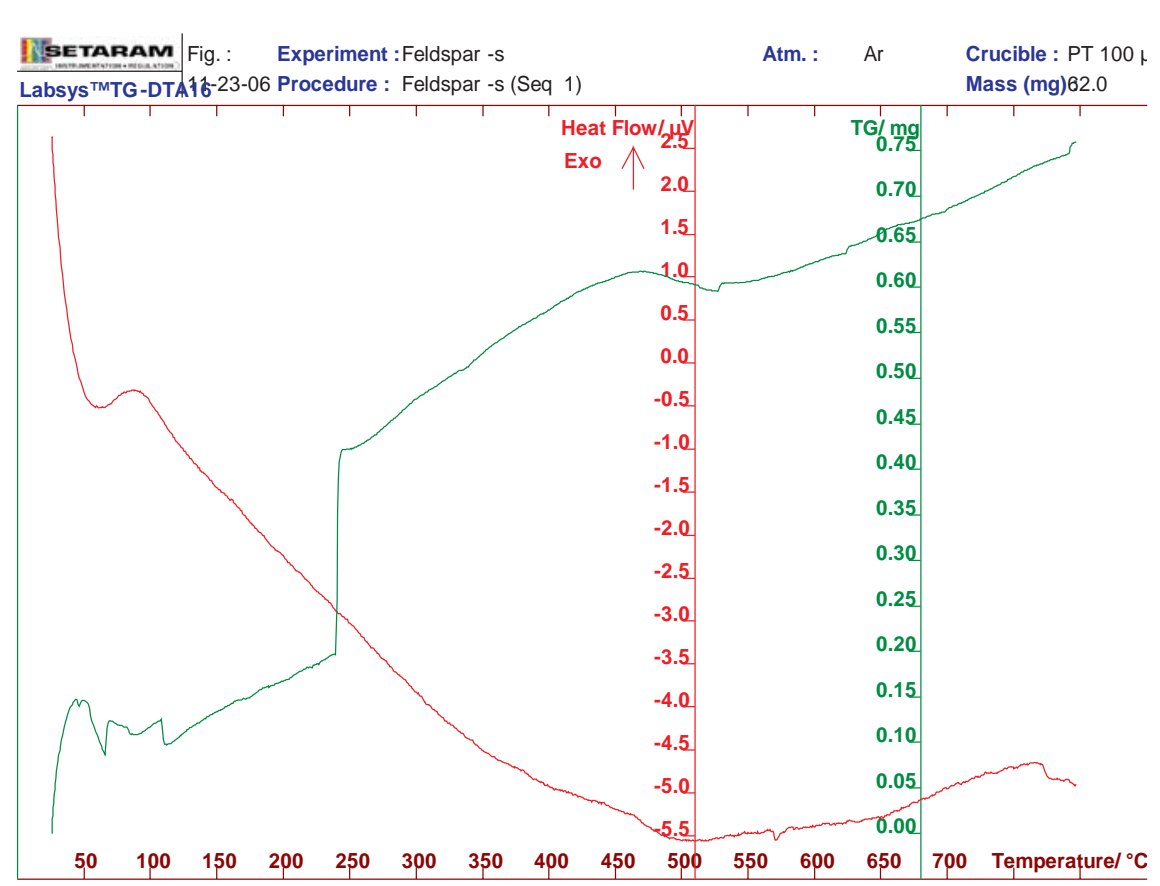

2(d) DTA/TGA curves of feldsper 


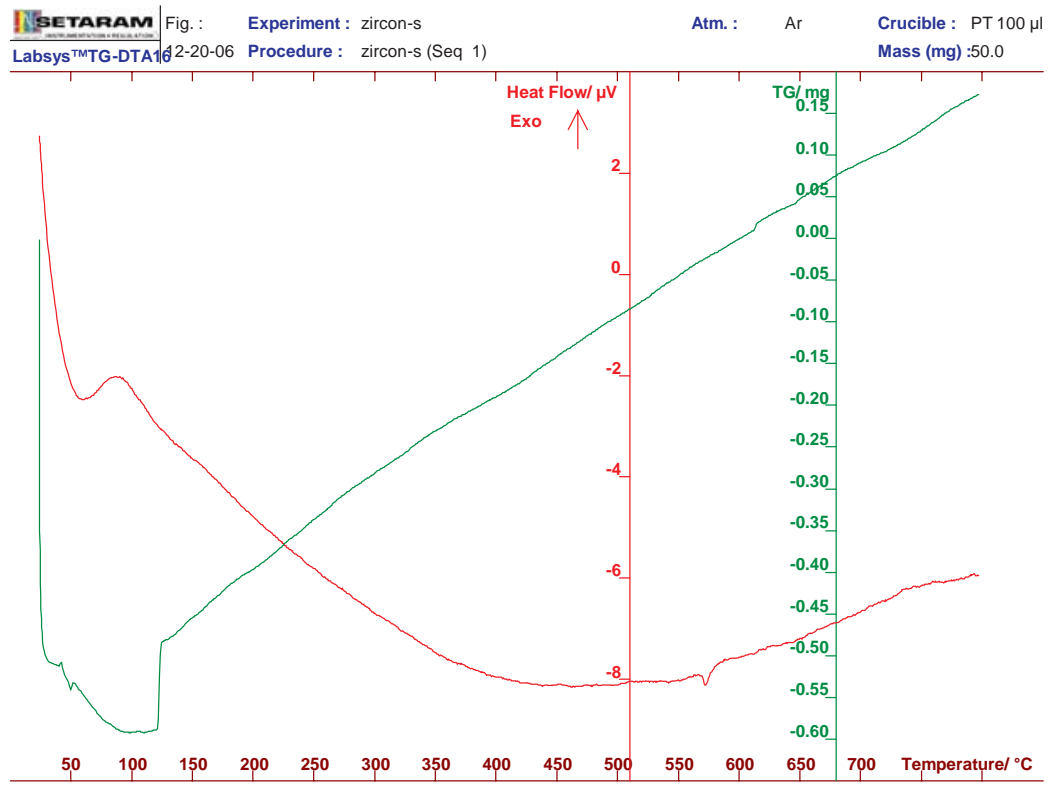

Figure 2(e) DTA/TGA curves of zircon

which is likely due to the loss of bound water present in clay samples. The weight changes observed in TGA are clearly evident as endothermic change in DTA curves. Both TGA and DTA results also indicate that the clays are kaolinitic in nature. The DTA curve of quartz (Fig. 2c) shows the usual endothermic peak at $573^{\circ} \mathrm{C}$ due to a transition from modification $\beta$ to modification a which is also associated with volume increase by approximately $1.5 \% 7$. The DTA curves of feldspar and zircon (Fig. 2d and 2e) are almost flat and do not yield any characteristic heat effects. Both zircon and feldspar show a small endothermic effect evident at $575^{\circ} \mathrm{C}$ due to the presence of quartz. (ii) Physical characteristics of prepared tile samples and comparison with commercial tiles

To assess the quality of the tile bodies, primarily physical characteristics were considered. Figure 3 shows the firing shrinkage behaviour of the prepared tiles specimens. It is clear from this bar diagram that the tile bodies $\mathrm{C}$ and $\mathrm{D}$ posses low firing shrinkage compared to the other 3 samples. Firing shrinkage is one of the important criteria representing the quality of the tiles and a lower value of firing shrinkage is always desired to the researchers. The differences in chemical and or mineralogical behaviour of the raw materials no doubt controls the firing shrinkage and the low firing shrinkage value of tiles $\mathrm{C}$ 


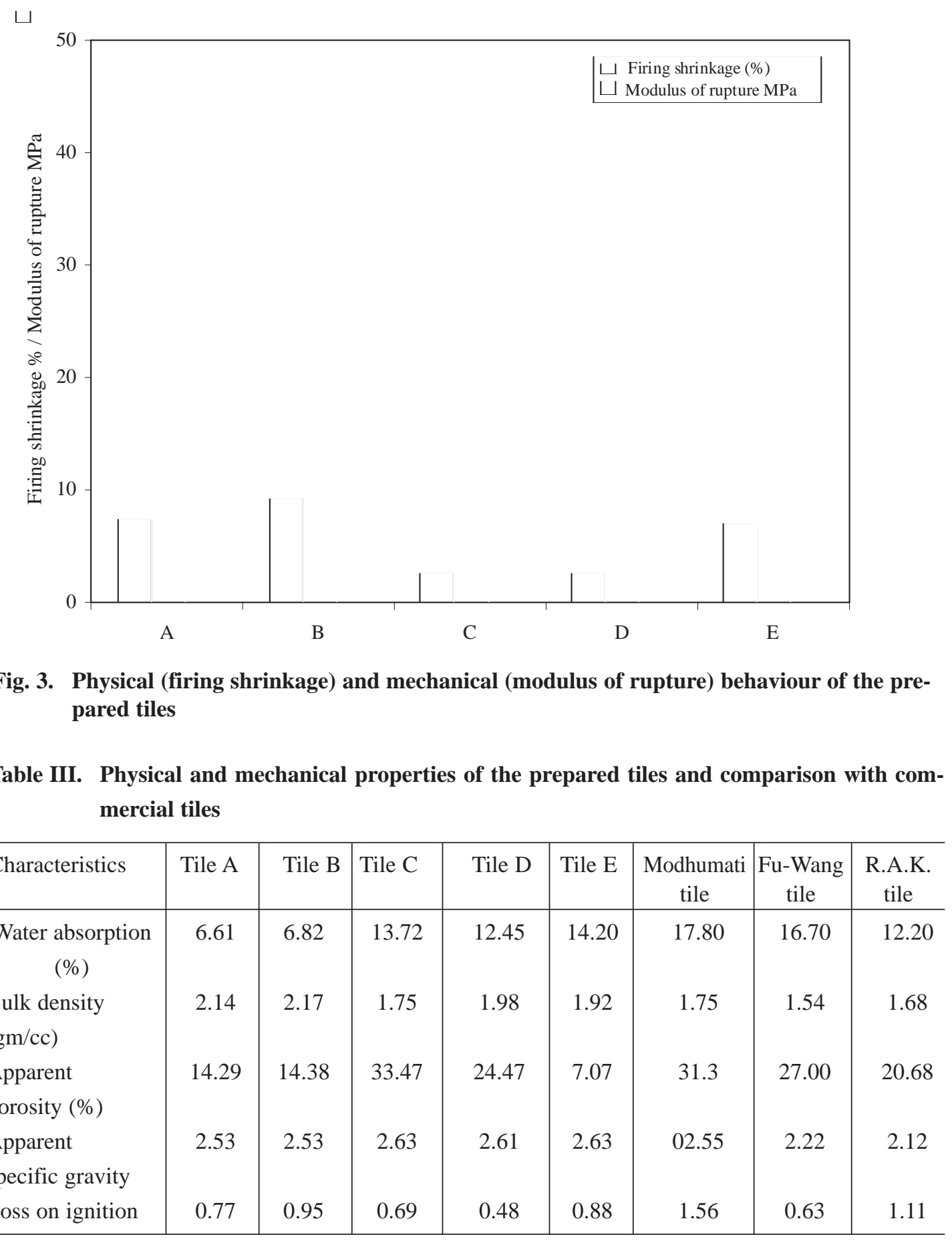


and $\mathrm{D}$ could be due to the presence of higher siliceous materials in their compositions.

It should be noted here that as we collected the commercially available tiles in fired and finished form, we could not compare the firing shrinkage behaviour of our tiles with the commercial tiles. However, we have determined and compared other physical properties of the commercial tiles with the experimental tiles and the results are shown in Table III.

Measurement of water absorption, bulk density, porosity and specific gravity are the tools for determining the degree of maturation or vitrification of a ceramic body. It is evident from Table III that numerical values of water absorption of all the compositions are within the range of that of wall tiles (Komar). Bulk density of the tiles composi- tions $\mathrm{C}, \mathrm{D}$ and $\mathrm{E}$ is in the range with a smalvariation, but in case of tiles $\mathrm{A}$ and $\mathrm{B}$ the value is higher. However, values of water absorption of these later 2 tiles are lower than the value range of wall tiles and higher than that of floor tiles (Komar). Considering all these factors although it seems that tiles C, D and E are better than tiles A and B, but from the firing shrinkage behaviour it has already been shown that the compositions of tiles $\mathrm{C}$ and $\mathrm{D}$ are much better. The values of modulus of rupture (MOR) or bending strength of tile $\mathrm{C}$ and $\mathrm{D}$ (Fig. 3) are higher than that of tiles $\mathrm{A}, \mathrm{B}$ and $\mathrm{E}$ which also justifies the better quality of tiles $C$ and $D$. So in view of the physical properties, comparing with the locally available tiles, the prepared tiles specifically composition $\mathrm{C}$ and $\mathrm{D}$ satisfies the desired quality of tiles.

Table IV. Chemical analysis of the prepared tiles and commercial tiles

\begin{tabular}{l|c|c|c|c|c|c|c|c}
\hline $\begin{array}{l}\text { Parameters } \\
\text { measured (\%) }\end{array}$ & Tile A & Tile B & Tile C & Tile D & Tile E & Madhumati & R.A.K & $\begin{array}{c}\text { Fu- } \\
\text { Wang }\end{array}$ \\
\hline $\mathrm{Al}_{2} \mathrm{O}_{3}$ & 27.12 & 27.17 & 29.23 & 20.57 & 32.29 & 18.28 & 20.63 & 21.10 \\
$\mathrm{SiO}_{2}$ & 63.88 & 63.83 & 64.23 & 69.03 & 59.99 & 54.04 & 68.78 & 67.20 \\
$\mathrm{Na}_{2} \mathrm{O}$ & 0.53 & 0.55 & 0.19 & 0.38 & 0.29 & 0.20 & 0.24 & 0.60 \\
$\mathrm{~K}_{2} \mathrm{O}$ & 4.35 & 4.24 & 1.19 & 1.92 & 2.40 & 1.61 & 1.15 & 2.41 \\
$\mathrm{CaO}$ & 0.19 & 0.17 & 0.25 & 0.58 & 0.20 & 18.12 & 4.06 & 0.25 \\
$\mathrm{TiO}_{2}$ & 1.58 & 1.52 & 2.46 & 1.92 & 2.17 & 2.62 & 1.25 & 1.15 \\
$\mathrm{Fe}_{2} \mathrm{O}_{3}$ & 1.25 & 1.24 & 1.47 & 0.74 & 1.52 & 3.84 & 2.63 & 4.81 \\
$\mathrm{ZrO}_{2}$ & -- & -- & -- & 4.12 & -- & -- & -- & 0.26 \\
$\mathrm{Others}$ & 0.33 & 0.33 & 0.29 & 0.26 & 0.26 & 0.17 & 0.25 & 0.32 \\
\hline
\end{tabular}


(iii) Chemical analyses of prepared tile samples and comparison with commercial tiles

The results of the chemical analyses of the experimental and commercial tiles are shown in Table IV. It is clear from this analyses that the oxide percentage / constituents present in prepared tiles was not varied significantly. This indicates that the combination or mixture of the raw materials have little effect in chemical characteristics. However, due to the differences in mineralogical behaviour of the raw materials, a significant variation in firing shrinkage is found as expected which has already been discussed in the previous section. The chemical compositions of the experimental tiles are within the range of that present in the commercial tiles confirmed that the ratio of the raw materials used here are acceptable for the manufacture of wall tiles but the combination needs to be optimized from the point of mineralogical behaviour of the raw materials in order to have the minimum firing shrinkage effect, which ultimately will reduce the bending of the tiles during firing.

\section{Conclusion}

The present investigation revealed that quality tiles can be manufactured using different ratios of the local raw materials (clay, quartz, feldspar and zircon) with molasses (a waste product of sugar industry) as binder. Particularly tiles specimen C and D satisfies the properties of quality tiles which reflect that among the five combinations investigated, the combinations of raw materials for these two varieties can be optimized for the production of quality tiles. However, further investigation is going on to produce such tiles on pilot plant scale.

\section{Acknowledgement}

We are grateful to BCSIR authority for funding and we particularly acknowledge the assistance of Dr. Kazi Nasrin Farooque, CSO, IGCRT for DTA/TGA and Mr. Mainul Ahsan PSO for XRF experiments.

\section{References}

ASTM, Designation: C 373 - 88. Standard Test Method for water absorption, bulk density, apparent porosity and apparent specific gravity of fired white ware products.

Das, S. K. Dana, K. Singh and V. Sarkar, R. Shrinkage and Strength (2005) behaviour of quartzitic and kaolinitic clays in wall tile composition, Applied Clay Science, 29137 $-143$.

Halm, L. (1952) Comparative study of American and French Flint Clays, J. Am. Ceramic Bullletin, 31(3): 79 - 84.

Komar, A. Building Materials and Component, Mir Publishers, Moscow. 
Olgun, A. Erdogan, Y. Ayhan Y. and Zeybek, B. (2005) Development of ceramic tiles from coal fly ash and tincal ore waste, Ceramics International, 31: 153 - 158.

Ramachandran V. S. (1969) Applications of differential thermal analysis in cement chemistry, Chemical Publishing Company, INC. New York.
Shah H. M. and Maity, K. N. (2001) Development of glazed tile through optimal utilization of fly ash, Trans. Indian Ceram. Soc. 60(3): 145 - 149.

Yatsenko, N. D. Zubekhin A. P. and Rakova, V. P. (1998) Low shrinkage ceramic tiles, Glass Cearm., 55 (7 - 8) 255 - 257.

Received : July 03, 2007;

Accepted : October 07, 2007 